\title{
STUDY OF NANO-HYDROXYAPATITE/ZIRCONIA STABILIZED WITH YTTRIA IN BONE HEALING: HISTOPATHOLOGICAL STUDY IN RABBIT MODEL
}

\author{
Gholamreza Abedi ${ }^{1}$, Amirali Jahanshahi ${ }^{1}$, Mohamad hosein Fathi ${ }^{2}$, Iraj Sohrabi Haghdost ${ }^{3}$, \\ ABAs VeshKINI ${ }^{4}$
}

${ }^{1}$ Department of Surgery, Faculty of Specialized Veterinary Sciences, Science and Research Branch, Islamic Azad University, Tehran, Iran

${ }^{2}$ Department of Materials Engineering, Isfahan University of Technology, Isfahan, Iran

${ }^{3}$ Department of Pathology, Faculty of Specialized Veterinary Sciences, Science and Research Branch, Islamic Azad University, Tehran, Iran

${ }^{4}$ Department of Radiology, Faculty of Specialized Veterinary Sciences, Science and Research Branch, Islamic Azad University, Tehran, Iran

\begin{abstract}
Acceleration of bone healing has always been a major challenge in orthopedic surgery, the aim of this study was an evaluation of the biological effects of zirconia-stabilized yttria on bone healing, using an in vivo model.

Nano-hydroxyapatite powder with zirconia-stabilized yttria were inserted in rabbit tibia and then histologically analyzed and compared with non-treated controls so thirty six. New Zealand white male rabbits randomly divided into two groups of 18 rabbits each. A cortical hole of $4 \mathrm{~mm}$ diameter and $8 \mathrm{~mm}$ depth in each tibia was drilled. In group I, the defect was left empty, whereas in group II, the bone defect was packed with nano-hydroxyapatite $/ 5 \%$ zirconia stabilized with yttria. Histological evaluations were performed at two, four and six weeks after the implantation.

Microscopic changes on two groups along with the time course were scored and statistical analysis showed that the average scores in group II were significantly higher than the other groups $(\mathrm{p}<0.05)$.

Histological analysis was shown to be significantly improved by the nano-hydroxyapatite $/ 5 \%$ zirconia stabilized with yttria compared with the control group, suggesting that this biomaterial promote the healing of cortical bone, presumably by acting as an osteoconductive.
\end{abstract}

Key words: zirconia-stabilized yttria, bone healing, histological changes, rabbits.

\section{Introduction}

Acceleration of bone healing in the fracture site has always been a major problem. Fresh autologous spongy bone transplantation is considered as the gold standard for bone grafts [1,2]. As compared with other methods the progenitor cells are provided without stimulation of an immune system response. But it has some problems, including donor site damage and limitation of harvested amount. These restrictions encourage researchers to use synthetic bone graft substitutes $[3,4]$.

In the field of matrix-based tissue-engineering approaches the goal is to use structural implants and/or materials to replace the defective bone [5, 6]. These approaches depend on the recruitment of endogenous 
osteoinductive factors and migration of osteogenic cells to regenerate the bone defect $[7,8]$. If the scaffold could induce cells from the surrounding tissues, pre-expansion of the cells for the transplantation would not be required [9]. After insertion of a material to the damage site, it will be exposed to adjacent cells, resulting in captured repair cells and the possibility of leakage and non-homogeneous scatter will be decreased. Various materials $[1,2,10]$ have been developed for these purposes: ceramics $[11,12]$, polymers $[13,14]$, metals $[15,16]$ and composites $[1,17,18]$. However, complete success has not yet been achieved in the use of these materials [14, 15], because their physical structures are different from bones. Furthermore, they may have osteoconductive but normally not osteoinductive properties and can only act as a matrix for new osseous ingrowth and slow creeping substitution. The time-consuming process of resorption is also a problem [14].

Hydroxyapatite $\left[\mathrm{HA}, \mathrm{Ca}_{10}\left(\mathrm{PO}_{4}\right)_{6}(\mathrm{OH})_{2}\right]$, a major inorganic component of bone, has been used extensively in biomedical applications and bone regeneration due to its biodegradable, bioactive, and osteoconductive properties. However, usage of pure HA is limited on account of the principal limitation of this material - weakness and brittleness - which restricts its clinical orthopedic and load-bearing applications. Therefore, the need to improve the mechanical properties of HA has attracted wide attention [19, 20].

Depending on the application, there is often a need for the nanoparticles to be in a particular size range. There are various techniques reported in the literature for the production of nano-sized hydroxyapatite particles, but none report the effects of processing parameters on particle size and morphology. The techniques include mechanochemical synthesis, combustion preparation, and various wet chemistry techniques, such as direct precipitation from aqueous solutions, sol-gel procedures, hydrothermal preparation and emulsion synthesis routes [19, 20]. The solgel technique has advantages over other techniques as it does not require $\mathrm{pH}$ control, high temperature, vigorous agitation or long hydrolysis times, which contribute to it being one of the most commonly used processing methods for nanomaterials $[19,20]$.

Zirconium is widely used to build prosthetic devices because of its good mechanical and chemical properties. Yttria-stabilized zirconia (YSZ) is a zirconium-oxide based ceramic, in which the particular crystal structure of zirconium oxide is made stable at room temperature by the addition of yttrium oxide. These oxides are commonly called "zirconia" $\left(\mathrm{ZrO}_{2}\right)$ and "yttria" $\left(\mathrm{Y}_{2} \mathrm{O}_{3}\right)$, hence the name. Zirconium is used to manufacture materials that work in aggressive environments, such as extrusion dyes, valves and port liners for combustion engines [21]. It has good chemical and dimensional stability, high mechanical strength and toughness, and a Young's modulus similar to that of stainless steel alloy [22].

Zirconium is a bio-inert non-resorbable metal oxide which has been used in dental implants [23] and in femoral heads of total hip replacements. In this case zirconium ball heads have shown an ultimate compressive load that is 2-2.5 times higher than that of aluminum oxide heads [22]. Zirconium implants have excellent resistance to corrosion and a high wear resistance: they have also shown high biocompatibility and high values of bending strength and fracture toughness $[21,24]$. Cell proliferation kinetics and total protein synthesis in osteoblast culture studies with zirconium were similar to those observed in control cells cultured on glass coverslips [24]. Zirconium's ivory color, similar to the color of natural tooth [25], makes it useful in esthetically important areas of the oral cavity [26], and its ability to transmit light renders it a suitable material in esthetic restorations [26]. Good biocompatibility of this material was found in animal studies with direct bone apposition to the implants $[23,27]$. Zirconium can also be prepared as a colloidal suspension and then used to coat surfaces for improving their characteristics [28].

The aim of this study was to evaluate the biological effects of a combination of nano-hydroxyapatite zirconia-stabilized yttria made with sol-gel methods on bone healing, using an in vivo model: nano-hydroxyapatite powder with zirconia-stabilized yttria was inserted in rabbit tibia and then histologically analyzed and compared with non-treated controls.

\section{Material and methods}

All rabbits of the present research were kept according to the norms of the Islamic Azad University Faculty of Specialized Veterinary Sciences, Tehran, Iran, laboratory of animal experimentations; this investigation was approved by the Committee of Ethics in Research with animals in Islamic Azad University. The study was designed so as to minimize the number of animals required for the experiments.

\section{Scaffold preparation}

First the biomaterial was made with the sol-gel method. In this method nano-hydroxyapatite powder was initially made, then $5 \% \mathrm{ZrO}_{2}$ substrate added to it. Briefly, a phosphite sol was prepared by hydrolyzing triethyl phosphite $\left(\left(\mathrm{C}_{2} \mathrm{H}_{5} \mathrm{O}\right)_{3} \mathrm{P}\right.$, Fluka) for $24 \mathrm{~h}$ with a fixed amount of distilled water and ethanol absolute (the molar ratio of water and ethanol to phosphite was fixed at 4) in a sealed glass container under vigorous stirring at room temperature. A stoichiometric amount of calcium nitrate tetrahydrate $\left(\mathrm{Ca}\left(\mathrm{NO}_{3}\right)_{2} \cdot 4 \mathrm{H}_{2} \mathrm{O}\right.$, Merck) dissolved in ethanol absolute was added dropwise into the hydrolyzed phosphite sol. The concentration of the calcium and phosphorus solution was 


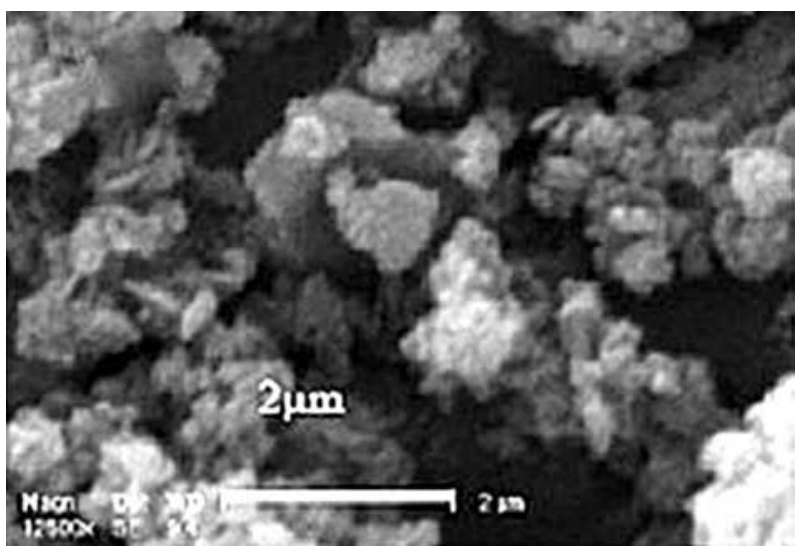

Fig. 1. SEM micrographs of HA-ZRY composite nanopowders

kept constant to maintain the stoichiometry of HA. Vigorous stirring was continued for an additional 24 $\mathrm{h}$ after titration. Zirconium isopropoxide isopropanol complex $\left(\mathrm{Zr}\left(\mathrm{OC}_{3} \mathrm{H}_{7}\right)_{4} \mathrm{OC}_{3} \mathrm{H}_{8}\right.$, Aldrich) diluted in 2-propanol (Merck) was used as the source of zirconia. Yttrium (III) acetate hydrate $\left(\left(\mathrm{CH}_{3} \mathrm{CO}_{2}\right)_{3} \mathrm{Y}_{-} \mathrm{xH}_{2} \mathrm{O}\right.$, Sigma) and glacial acetic acid ( $\mathrm{AcH}$ ) were used as stabilizing agents. The first step in the formation of zirconia sol is to obtain a stable sol, which consists of zirconia sol and yttrium acetate. Firstly, zirconia sol was prepared and then mixed with yttrium acetate. Glacial acetic acid was dripped into the zirconia sol to form a complex compound by the reaction of $\mathrm{AcH}$ with $\mathrm{Zr}\left(\mathrm{OC}_{3} \mathrm{H}_{7}\right)_{4} \mathrm{OC}_{3} \mathrm{H}_{8}$. The greater reactivity of $\mathrm{Zr}$ $\left(\mathrm{OC}_{3} \mathrm{H}_{7}\right)_{4} \mathrm{OC}_{3} \mathrm{H}_{8}$ demands strict control over the hydrolysis conditions in order to prepare a homogeneous sol rather than a precipitate. As the hydrolysis reaction can take place even in an atmosphere of low humidity, hydrolysis conditions were strictly controlled. Thus, the glass containers used to contain the solutions were covered with plastic wraps to inhibit evaporation. The yttria precursor was obtained by solubilization of 5 mol\% yttrium acetate in 2-propanol. After the addition of yttrium acetate to the zirconia sol, distilled water was dripped into the mixed solution. The source solution was homogenized with stabilizing agents under vigorous stirring for $24 \mathrm{~h}$. No catalytic agent was used in this work and the mixed solution was prepared at room temperatures of $20-25^{\circ} \mathrm{C}$. The molar ratios of water to $\mathrm{Zr}$, 2-propanol to $\mathrm{Zr}$, and acetic acid to $\mathrm{Zr}$ were set at $50: 1$ respectively. The reinforcements were prepared by $30 \mathrm{wt} \% \mathrm{ZrO}_{2}$ sol concentration. Finally, a mixture of the zirconia sol and the hydroxyapatite sol was used to synthesize HA-YSZ composites. Fortunately, no gelation was observed despite the addition and a stable HA-YSZ composite sol was achieved. The reinforcement solutions were constantly stirred for $24 \mathrm{~h}$ followed by $4 \mathrm{~h}$ of aging. After aging, the obtained gels were oven dried at $80^{\circ} \mathrm{C}$ and calcined at 850,950 , and $1050^{\circ} \mathrm{C}$ for $1 \mathrm{~h}$ to obtain crystalline powders. Therefore, one type of zirconia, namely pure,
5 mol\% yttria doped, was used to make the HA-YSZ composite powder specimens.

\section{Scanning electron microscopy}

The surface morphology of scaffolds was characterized using a scanning electron microscope (SEM, Philips XL30, Netherlands) after specimens were coated with gold using a sputter coater (Fig. 1).

\section{Description of operative procedures}

In this experimental study, 36 male adult white New Zealand rabbits were utilized (weight: 3 to $3.5 \mathrm{~kg}$ ), purchased from Pasteur Institute of Iran (Tehran, Iran). Prior to the surgery, the rabbits were housed in a standard cage with food and water ad libitum and allowed to acclimate to their environment for a period of at least 7 days so as to ensure their health and stability. They were divided randomly into two experimental groups of 18 rabbits each. Anesthesia was induced using intramuscular ketamine hydrochloride $(20 \mathrm{mg} / \mathrm{kg})$, acepromazine $(0.1 \mathrm{mg} / \mathrm{kg})$ and atropine sulfate $(0.02$ $\mathrm{mg} / \mathrm{kg}$ ). Rabbits were immobilized and connected to an anesthetic machine using isoflurane $1 \%$. Then the left tibias were shaved, washed and disinfected with povidone-iodine. A $5-7 \mathrm{~cm}$ incision was made on the proximal-anterior part of tibias. The incision penetrated the epidermis, dermis and the fascial layers. An additional medial-anterior incision was made through the periosteum. The periosteum was elevated with a periosteal elevator and retained by a self-retaining retractor. A cortical hole of $3 \mathrm{~mm}$ diameter and $8 \mathrm{~mm}$ depth in each tibia was drilled. The bone cavities were washed with saline during and after the drilling. In group I, the defect was left empty, whereas in group II, the bone defect was packed with nano-hydroxyapatite $/ 5 \%$ zirconia stabilized with yttria. After implantation, muscles and fascia were sutured with vicryl 5-0 and skin was sutured with nylon 3-0 cefazolin $(22 \mathrm{mg} / \mathrm{kg})$ and the analgesic ketoprofen $(2 \mathrm{mg} / \mathrm{kg})$ was used via intramuscular administration for 5 post-operative days. Rabbits were allowed to move without any restrictions immediately after recovery from the anesthesia.

\section{Visual observations}

Six rabbits in each group were sacrificed at the end of two, four and six weeks. The surgical site was carefully inspected, special attention being paid to:

- signs of foreign body or inflammatory reaction such as swelling or seromas,

- appearance of the implant sites (healing, tissue integration).

\section{Histological evaluation}

The left tibias were harvested at the designated time points. The specimens were harvested with the 
Table I. Histological scoring

\begin{tabular}{|c|c|c|c|c|}
\hline \multirow{2}{*}{ Parameters } & \multicolumn{4}{|c|}{ SCORES } \\
\hline & 0 & 1 & 2 & 3 \\
\hline $\begin{array}{c}\text { collagen fibers } \\
\text { orientation }\end{array}$ & no collagen fibers & woven & woven + laminar & laminar \\
\hline trabecular thickness & 0 & $20 \mu>$ & $20 \mu<-<60 \mu$ & $>60 \mu$ \\
\hline inflammation & $\begin{array}{l}\text { severe presence of } \\
\text { inflammatory cells }\end{array}$ & $\begin{array}{l}\text { notable presence of } \\
\text { inflammatory cells }\end{array}$ & $\begin{array}{l}\text { presence of a few } \\
\text { inflammatory cells }\end{array}$ & $\begin{array}{c}\text { no } \\
\text { inflammatory cells } \\
\text { present }\end{array}$ \\
\hline $\begin{array}{l}\text { foreign body } \\
\text { reaction }\end{array}$ & - & - & - & + \\
\hline vitality & $\begin{array}{c}\text { no osteocytes in } \\
\text { lacuna }\end{array}$ & osteocytes in lacuna & osteocytes in lacuna & osteocytes in lacuna \\
\hline
\end{tabular}

surrounding tissue and fixed in $10 \%$ neutral formalin for two weeks, then were decalcified with $10 \%$ nitric acid, dehydrated, and then embedded in paraffin, and after that were sectioned at $5 \mu \mathrm{m}$ and stained with hematoxylin-eosin for histological observation. Assessment was performed by a blinded assessor while considering parameters in Table I, with an Olympus BH-2 light microscope (Tokyo, Japan). Measurements were made on four sections for each sample.

Differences between groups were evaluated by Kruskal-Wallis and analysis of variance (ANOVA) tests. P-values $<0.05$ were considered statistically significant. Statistical analysis was performed using the SPSS statistics package version 15.0.15.

\section{Results}

\section{Visual observations}

By visual evaluation it was possible to see that the operative site in group II was partially healed, without any evidence of inflammation or swelling at two weeks (Fig. 3D), but in group I no evidence of heal-

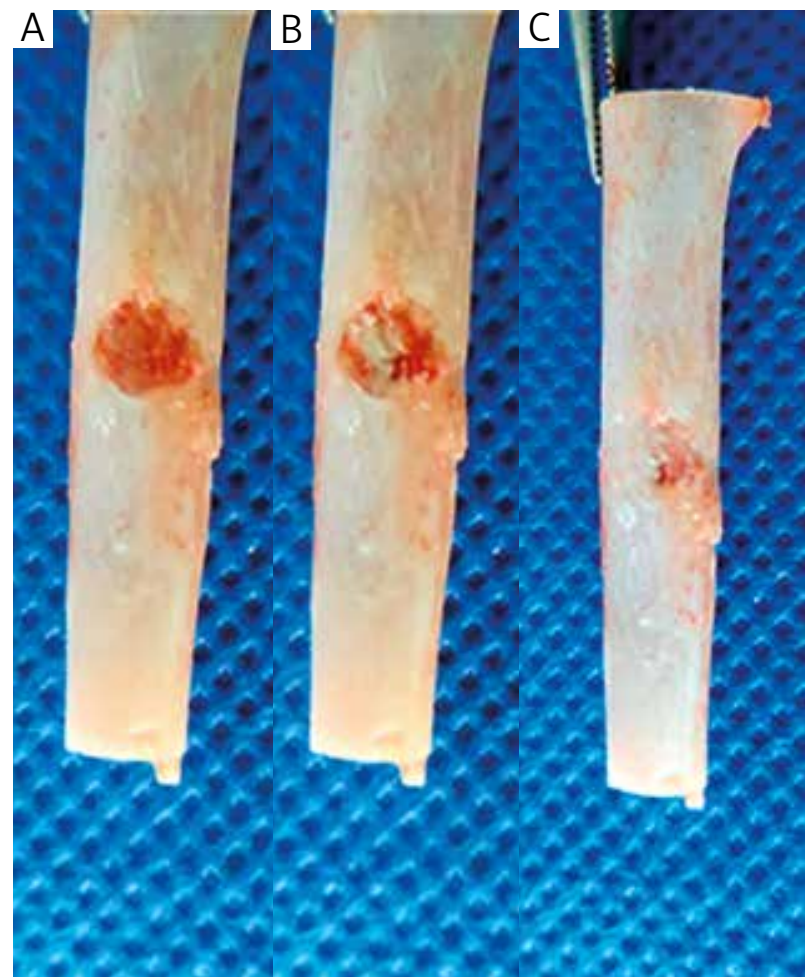

Fig. 2. Photographs of tibia taken after the euthanization of the animals in control groups after 2 weeks (A), 4 weeks (B) and 6 weeks (C)

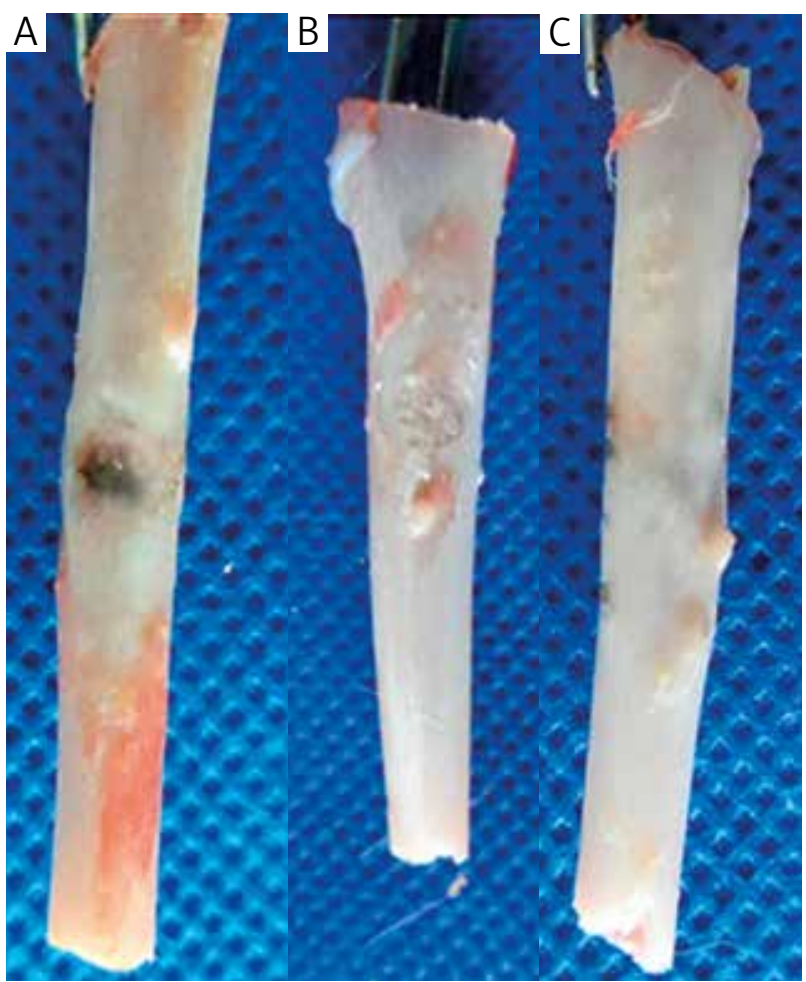

Fig. 3. Photographs of tibia taken after the euthanization of the animals in treatment groups after 2 weeks (A), 4 weeks (B) and 6 weeks (C) 

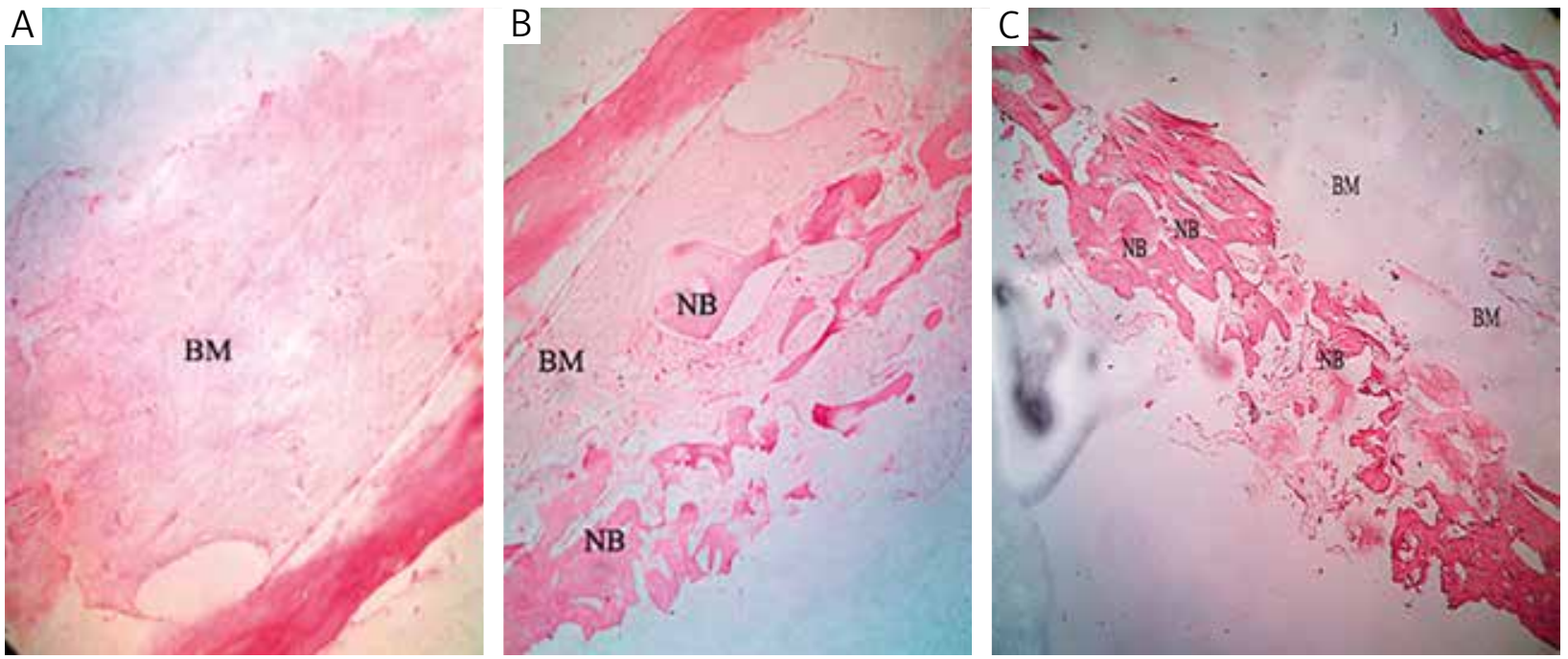

Fig. 4. Hematoxylin-eosin stained sections of control groups which were harvested at 2 (A), 4 (B) and 6 (C) weeks (magnification: $4 \times 10$ ). In the photos, NB denotes newly formed bone tissue, while BM denotes bone marrows.

ing was present (Fig. 2A). The tibial bone appeared healthy, without any manifestation of inflammatory or degenerative signs after four weeks and the implantation site in group II was completely filled with new bone formation (Fig. 3E), and in group I the evidence of healing was present (Fig. 2B) after six weeks. The surgical sites in group II were not always easily detectable and completely filled with mature bone (Fig. 3F) but in group I surgical sites were easily detectable (Fig. 2C).

\section{Histological evaluations}

\section{After two weeks}

In group II, there was very little inflammation and new bone formation was already present. Contact with bone graft material was also seen (Figs. 5, 6D), but in group I no evidence of new bone formation was present (Fig. 4A).
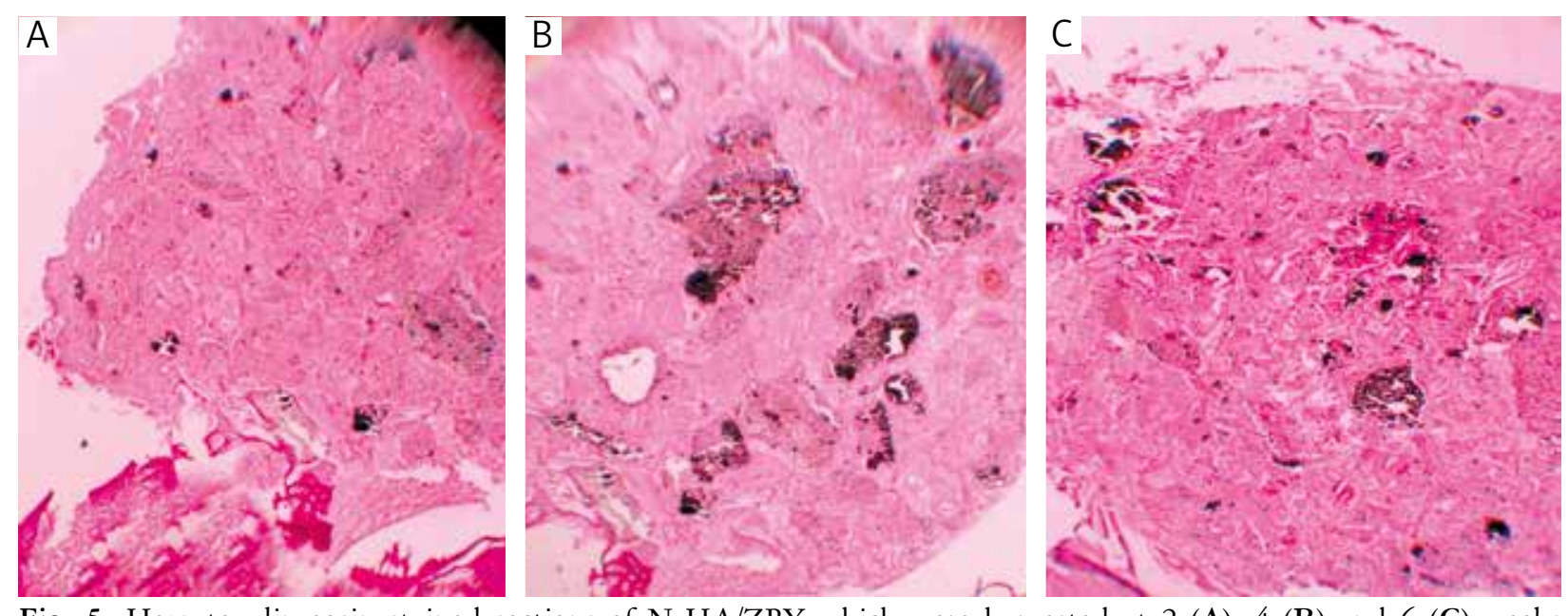

Fig. 5. Hematoxylin-eosin stained sections of N-HA/ZRY which were harvested at 2 (A), 4 (B) and 6 (C) weeks post-implantation (magnification: $4 \times 10$ )

\section{After four weeks}

The woven bone was formed in the control group (Fig. 4B). Mixed lamellar and woven bone formation was seen in group II and there was a little inflammation in this group. Foreign body reaction was negative. Bone growth was observed on either side (outside and inside) of the implant. Lacunas contained live osteocytes, and demonstrated active and vital bone (Figs. 5, 6E).

After six weeks

In group II, lamellar bone formation was observed and trabecular thickness was remarkable. The inflammation and foreign body reaction were negative. Partial contact with biomaterials and host bone was also seen (Figs. 5, 6F). In group I mixed lamellar and woven bone formation was seen and trabecular thickness was not remarkable (Fig. 4C). 

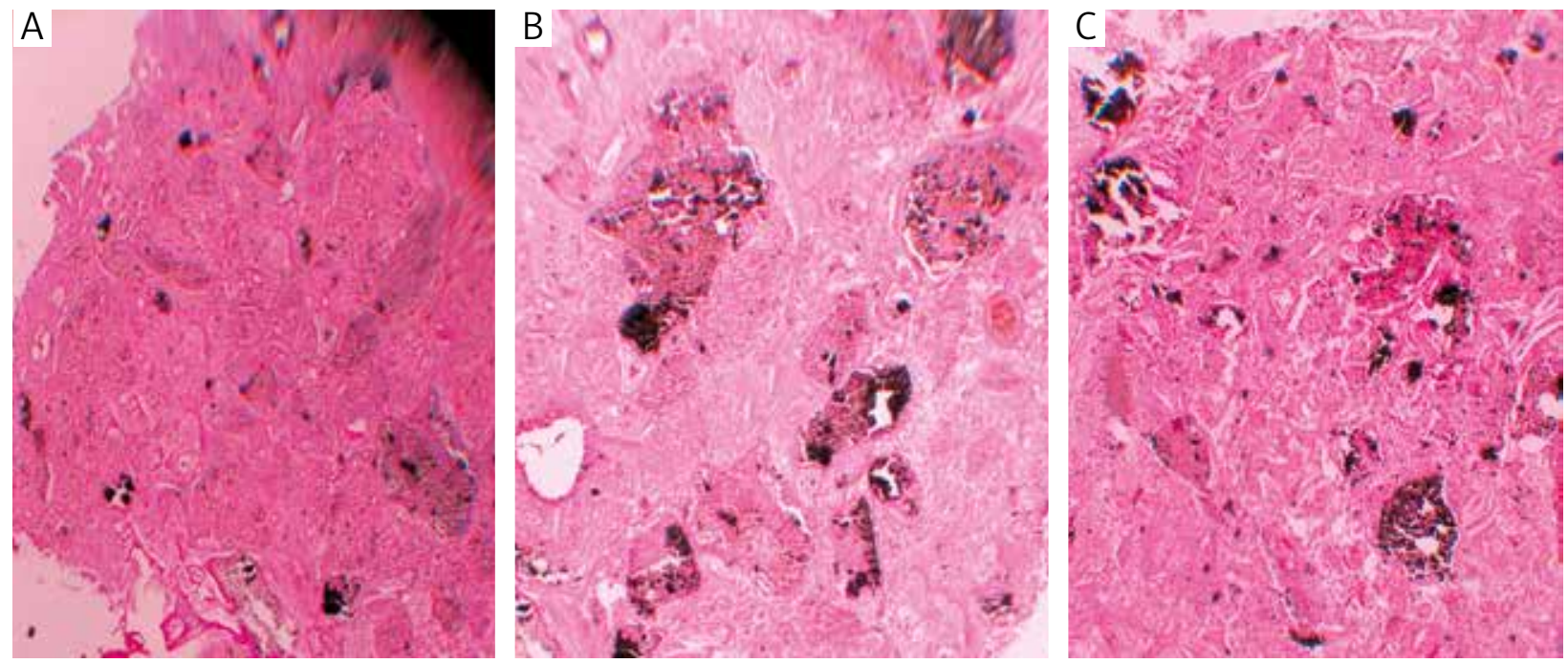

Fig. 6. Hematoxylin-eosin stained sections of N-HA/ZRY which were harvested at 2 (A), 4 (B) and 6 (C) weeks post-implantation (magnification: $10 \times 10$ )

Detailed results of histological evaluations are summarized in Table II. Histological changes in the two groups were scored and statistical analysis showed that the total average scores in group II were significantly higher than the control group $(\mathrm{p}<0.05)$.

\section{Discussion}

Ceramic biomaterials are widely used in orthopedics and dentistry as a consequence of their chemical and mechanical proprieties. For example, zirconia is used in prosthetic surgery of the hip, giving a prolonged life of the implant because of its low friction surface and low debris products. Ceramic materials also demonstrate high biocompatibility properties: zirconia has high affinity for bone tissue [23] and the bone-implant interface is similar to that seen around titanium implants [21]. Zirconia inserted into subcutaneous tissue determined only a small inflammatory cell infiltrate with the implant completely surrounded by thin fibrous connective tissue [25]. In other studies it was shown that zirconia did not present any signs of toxic, immune or carcinogenetic effects $[22,29]$ and had no oncogenic effects in vitro $[22,30]$. This material showed no chromosome aberrations and no carcinogenicity [31]; moreover, zirconia did not alter the cell ploidy or cell-growth rate in accordance with the absence of any inducing effects on DNA synthesis or proliferation [24]. Zirconium oxide is able to up- or down-regulate the expression of some genes. Specifically, zirconia is able to modulate immunity, vesicular transport and cell cycle regulation [32]. Given the above-mentioned advantages, the idea of using zirconia to cover prostheses has become popular in recent years. Zirconium oxide coating, in fact, is mainly used to enhance bone growth, to minimize friction and corrosion, and to improve biocompatibility of total joint prostheses [33]. It has extreme hardness and good tribological characteristics. When the coating is thick enough ( $>20 \_\mathrm{m}$ ), it can withstand high contact stresses and the wear rate is negligible. Low friction is accompanied by low bending torque on the fixation surfaces of prostheses [28]. An [34] showed that a porous $\mathrm{ZrO}_{2} / \mathrm{HA}$ porous composite scaffold has excellent mechanical properties, and cellular/tissue compatibility, and would be a promising substrate to achieve both

Table II. Bone repair histological scores

\begin{tabular}{|c|c|c|c|c|c|c|}
\hline \multirow{2}{*}{ Parameters (MAXIMUM SCORES) } & \multicolumn{2}{|c|}{ GROUPS AT 2 WEEKS } & \multicolumn{2}{|c|}{ GROUPS AT 4 WEEKS } & \multicolumn{2}{|c|}{ GROUPS AT 6 WEEKS } \\
\hline & I & $\mathrm{II}^{*}$ & I & $\mathrm{II}^{*}$ & I & $\mathrm{II}^{*}$ \\
\hline collagen fibers orientation & 0 & 0.9 & 0.34 & 1.69 & 1.02 & 2.4 \\
\hline trabecular thickness & 0 & 1.2 & 0.28 & 1.57 & 1.36 & 2.64 \\
\hline inflammation & 0.2 & 0.67 & 0.3 & 1.33 & 0 & 0.87 \\
\hline foreign body reaction & 0 & 1.6 & 0 & 1.83 & 0 & 1.4 \\
\hline vitality & 0 & 0.72 & 0.27 & 1.12 & 1.2 & 1.84 \\
\hline total & 0.2 & 5.09 & 1.19 & 7.54 & 3.58 & 9.15 \\
\hline
\end{tabular}


bone reconstruction and regeneration needed in the treatment of large bone defects. Another study demonstrated that the zirconia materials were biocompatible and the cell response was comparable to titanium, which still presents the implant material of choice for oral implant fabrication. Whether there is a correlation between the up-regulation of different genes on the modified zirconia surface (TZP-proc) at day 21 and reduced bone-to-implant contact especially at day 14 was investigated [35]. Stefanic et al. reported that the -TCP coating adhered firmly to the underlying substrate and showed strong resistance towards mechanical forces present during the implantation of the coated zirconia implant into the artificial bone. In addition, variations in the heating regime allow further control over the topography and possibly over the physico-chemical properties of the $\beta$-TCP coating. The achieved results of their study showed the very promising properties of the presented $\beta$-TCP coating for future biomedical applications on zirconia bone implants [36].

In the present study a new method for zirconia-stabilized yttria biomaterial preparation is presented and the effects on bone growth of this technique are evaluated. In the treated samples a higher and statistically significant bone healing percentage was found. A high number of histological sections were evaluated. The rabbit was chosen as an experimental animal due to its low cost and ease of treatment. The time-scale of six weeks was chosen because rabbits have a higher metabolism and bone turnover than humans, and at six weeks healing is almost complete.

\section{Conclusions}

Histological analysis of the bone healing was shown to be significantly improved by nano-hydroxyapatite $/ 5 \%$ zirconia stabilized with yttria compared with the control group, suggesting that this biomaterial promotes the healing of cortical bone, presumably by acting as an osteoconductive material.

\section{Acknowledgment}

The authors wish to acknowledge the Faculty of Specialized Veterinary Sciences, Islamic Azad University, Science and Research Branch, Tehran, Iran, Research Council for approval and financial support of this research work.

Authors declare no conflict of interests.

\section{References}

1. Finkemeier CG. Bone-grafting and bone-graft substitutes. J Bone Joint Surg Am 2002; 84: 454-464.

2. Bauer TW, Muschler GF. Bone graft materials. An overview of the basic science. Clin Orthop 2000; 371: 10-27.
3. Banwart JC, Asher MA, Hassanein RS. Iliac crest bone graft harvest donor site morbidity. A statistical evaluation. Spine 1995; 20: 1055-1060.

4. Kurtz LT, Garfin SR, Booth Jr RE. Harvesting autogenous iliac bone grafts. A review of complications and techniques. Spine 1989; 14: 1324-1331.

5. Reddi AH. Symbiosis of biotechnology and biomaterials: application in tissue engineering of bone and cartilage. J Cell Biochem 1994; 56: 192-195.

6. Sepulveda P, Ortega FS, Innocentini MD, Pandolfelli VC. Properties of highly porous hydroxyapatite obtained by the gelcasting of foams. J Am Chem Soc 2001; 83: 3021-3024.

7. Bruder SP, Fox BS. Tissue engineering of bone: cell based strategies. Clin Orthop 1999; 367: 68-83.

8. Le Guehennec L, Layrolle P, Daculsi G. A review of bioceramics and fibrin sealant. Eur Cells Mater 2004; 8: 1-11.

9. Inui A, Kokubu T, Fujioka H, et al. Application of layered poly (L-lactic acid) cell free scaffold in a rabbit rotator cuff defect model. Sports Med Arthrosc Rehabil Ther Technol 2011; 3: 29-32.

10. Costantino PD, Friedman CD. Synthetic bone graft substitutes. Otolaryng Clin North Am 1994; 27: 1037-1074.

11. Bucholz RW. Nonallograft osteoconductive bone graft substitutes. Clin Orthop 2002; 395: 44-52.

12. LeGeros RZ. Properties of osteoconductive biomaterials: calcium phosphates. Clin Orthop 2002; 395: 81-98.

13. Palissery V, Taylor M, Browne M. Fatigue characterization of a polymer foam to use as a cancellous bone analog material in the assessment of orthopaedic devices. J Mater Sci Mater Med 2004; 15: 61-67.

14. Bilkay U. Comparing the osteogenic capacities of bone substitutes: hydroxyapatite, high-density porous polyethylene, and bone collagen: a biochemical and histological analysis. J Craniofac Surg 2004; 15: 585-593.

15. Zou X, Li H, Bunger M, et al. Bone ingrowth characteristics of porous tantalum and carbon fiber interbody devices: an experimental study in pigs. Spine J 2004; 4: 99-105.

16. Kujala S, Ryhanen J, Danilov A, Tuukkanen J. Effect of porosity on the osteointegration and bone ingrowth of a weight-bearing nickeltitanium bone graft substitute. Biomaterials 2003; 24: 4691-4697.

17. Sammarco VJ, Chang L. Modern issues in bone graft substitutes and advances in bone tissue technology. Foot Ankle Clin 2002; 7: 19-41.

18. Wang M. Developing bioactive composite materials for tissue replacement. Biomaterials. 2003; 24: 2133-2155.

19. Salehi S, Fathi MA. Fabrication and characterization of sol-gel derived hydroxyapatite/zirconia composite nanopowders with various yttria contents. Ceramics Int 2010; 36: 1659-1667.

20. Kong DJ, Young-Zhonh WU, Zheng Z. Mechanical properties of hydroxyapatite-zirconia coatings prepared by magnetron sputtering. Trans Nonferrous Met Soc China 2012; 2: 104-110.

21. Rosengren A, Pavlovic E, Oscarsson S, et al. Plasma protein adsorption pattern on characterized ceramic biomaterials. Biomaterials 2002; 23: 1237-1247.

22. Piconi C, Maccauro G. Zirconia as a ceramic biomaterial. Biomaterials 1999; 20: 1-25.

23. Akagawa Y, Ichikawa Y, Nikai H, Tsuru H. Interface histology of unloaded and early loaded partially stabilized zirconia endosseous implant in initial bone healing. J Prosthet Dent 1993; 69: 599-604.

24. Josset Y, Oum'Hamed Z, Zarriumpour A, Lorenzato M, Adnet J, Laurent-Marquin D. In vitro reactions of human osteoblasts in culture with zirconia and alumina ceramics. J Biomed Mater Res 1999; 47: 481-493.

25. Ichigawa Y, Akagawa Y, Nikai H, Tsuru H. Tissue compatibility and stability of a new zirconia ceramic in vivo. J Prosthet Dent 1992; 68: 322-326. 
26. Ahmad I. Yttrium-partially stabilized zirconium dioxide posts: an approach to restore coronally compromised nonvital teeth. Int J Periodont Rest Dent 1998; 18: 455-465.

27. Akagawa Y, Hosokawa R, Sato Y, Kameyama K. Comparison between freestanding and tooth-connected partially stabilized zirconia implants after two years function in monkeys: a clinical and histological study. J Prosthet Dent 1998; 80: 551-558

28. Lappalainen R, Anttila A, Heinonen H. Diamond coated total hip replacements. Clin Orthop Relat Res 1998; 352: 118-127.

29. Hulbert SF, Morrison SJ, Klavitter JJ. Tissue reaction to three ceramic of porous and non-porous structures. J Biomed Mater Res 1972; 6: 347-374.

30. Covacci V, Bruzzese N, Maccauro G, et al. In vitro evaluation of the mutagenic and carcinogenic power of high purity zirconia ceramic. Biomaterials 1999; 20: 371-376.

31. Piattelli A, Scarano A, Quaranta M. High precision, cost effective system for producing thin sections of oral tissues containing dental implants. Biomaterials 1997; 18: 577-579.

32. Carinci F, Pezzetti F, Volinia S, et al. Zirconium oxide: analysis of MG63 osteoblast-like cell response by means of a microarray technology. Biomaterials 2004; 25: 215-228.

33. Kim BK, Bae HE, Shim JS, Lee KW. The influence of ceramic surface treatments on the tensile load strength of composite resin to all-ceramic coping materials. J Prosthet Dent 2005; 4: 357-362.

34. An HS, Matsumoto T, Miyajima H, et al. Porous zirconia/hydroxyapatite scaffolds for bone reconstruction. Dental Materials 2012; 28: 1221-1231.

35. Kohal RF, Bächle M, Att W, et al. Osteoblast and bone tissue response to surface modified zirconia and titanium implant materials. Dental Materials 2013; 29: 763-776.

36. Stefanic M, Krnel K, Kosmac T. Novel method for the synthesis of a $\beta$-tricalcium phosphate coating on a zirconia implant.JEur Ceramic Soc 2013; 33: 3455-3465.

\section{Address for correspondence}

Amirali Jahanshahi

Department of Surgery

Faculty of Specialized Veterinary Sciences

Science and Research Branch

Islamic Azad University

Isla 127365634

Tehran, Iran

e-mail: Amirali.jahanshahi@gmail.com 